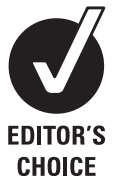

(

\section{See Editorial, p 1}

- An additional appendix has been published online only. To view this file please visit the journal online (http://oem.bmj. com/content/69/1.toc).

${ }^{1}$ Finnish Institute of Occupational Health, Lappeenranta, Finland ${ }^{2}$ Department of Physical Medicine and Rehabilitation, South Karelian Central Hospital, South Karelian District of Social and Health Services, Lappeenranta, Finland ${ }^{3}$ Department of Biomedical Engineering and Computational Science, Aalto University, Espoo, Finland

${ }^{4}$ Department of Physical Medicine and Rehabilitation, University of Oulu, Oulu, Finland ${ }^{5}$ National Institute for Health and Welfare, Centre for Health and Social Economics, Helsinki, Finland

${ }^{6}$ Evalua International, Espoo,

Finland

DDepartment of Public Health University of Helsinki, Helsinki, Finland

\section{Correspondence to}

Dr J Rantonen, Finnish Institute of Occupational Health (FIOH) Lappeenranta, Laserkatu 6, 53850 Lappeenranta, Finland; jarmo.rantonen@fimnet.fi

Accepted 14 April 2011 Published Online First 20 May 2011

The effectiveness of two active interventions compared to self-care advice in employees with non-acute low back symptoms: a randomised, controlled trial with a 4-year follow-up in the occupational health setting

\author{
J Rantonen, ${ }^{1}$ S Luoto, ${ }^{2}$ A Vehtari, ${ }^{3}$ M Hupli, ${ }^{2} \mathrm{~J}$ Karppinen, ${ }^{4}$ A Malmivaara, ${ }^{5}$ \\ S Taimela ${ }^{6,7}$
}

\section{ABSTRACT}

Objective Evaluate the effectiveness of two active interventions, aimed at secondary prevention of low back pain (LBP), in occupational health.

Methods We performed a survey of LBP $(n=2480$; response rate $71 \%$ ) and randomized 143 employees (66\% males, 45 years) with LBP over $34 \mathrm{~mm}$ on VAS into Rehabilitation $(n=43)$, Exercise $(n=43)$ or self-care $(n=40)$ groups. Primary outcomes were LBP, physical impairment (PI) and health-related quality of life ( $\mathrm{HROOL})$ for two years and sickness absence (SA) days during four years (LBP specific, total).

Results Compared to self-care, exercise reduced LBP at 12 months (mean difference (MD) $-12 \mathrm{~mm} ; 95 \% \mathrm{Cl}$ -21 to -2 ) and improved $\mathrm{HROOL}$ at 12 and 24 months (0.03; 0.00 to 0.05$)$, but did not reduce PI. The MDs of SA days in four years were -17 (-70 to 35 , total) and -15 (-47 to 13, LBP specific). Exercise reduced the probability of LBP specific SA during the third and fourth year. Compared to self-care, Rehabilitation reduced LBP at 3 months $(-10 \mathrm{~mm} ;-19$ to -1$)$ and 6 months $(-10 \mathrm{~mm} ;-20$ to -1$)$, but was not effective in $\mathrm{HROOL}$ or PI. The MDs of SA days in four years were $-41(-93$ to 8; total) and 5 ( -30 to 47; LBP specific). Rehabilitation reduced the probability of total $S A$ during first and second year and amount of total SA days in the fourth year.

Conclusions Among employees with relatively mild LBP, both interventions reduced pain, but the effects on SA and PI were minor. Exercise improved HROoL. The effect sizes were rather small.

Trial registration Number ClinicalTrials.gov NCT00908102.

\section{INTRODUCTION}

Low back pain (LBP) and consequent physical impairment at work have a significant socioeconomic impact as a result of temporary and permanent work disability. In industrialised countries, the lifetime cumulative incidence of LBP can be as high as $70 \%$ or more, and approximately $10 \%$ of cases become chronic. The rates of recurrent LBP are probably higher than those of chronic LBP. ${ }^{1}$

Occupational health $(\mathrm{OH})$ services, which are located close to workplaces, can be used to promote

\section{What this paper adds}

In the occupational health setting, the effectiveness of active low back pain (LBP) interventions in preventing chronic LBP and work disability is not fully known.

- Progressive exercises improved health related quality of life and reduced the probability of LBP specific sickness absence in employees with LBP.

- Multidisciplinary, hospital outpatient rehabilitation reduced the probability and length of any sickness absence but not those due to LBP.

- Progressive exercises and outpatient rehabilitation had some effect on pain, disability and painrelated fear.

- It seems possible to screen non-sick-listed employees with LBP symptoms into preventive intervention, although the optimal strategies need to be determined and further studies are required.

healthy practices to large groups of adults. Generally, $\mathrm{OH}$ services manage the work-related health and safety of employees. In Finland, $\mathrm{OH}$ physicians also take care of workers' general health (like family doctors or general practitioners) in addition to issues related to work and work ability, thus acting as an essential part of the national primary care system.

Most prior randomised controlled trials (RCTs) concerning LBP in the $\mathrm{OH}$ setting have focused on LBP patients already off work. ${ }^{2-6}$ In such groups, graded activity programmes (gradual but progressive increases in exercise $)^{7}$ and coordinated (multidisciplinary) care ${ }^{9} 10$ are known to enhance return to work. Some effect on pain and a decrease in negative work expectations was found in one RCT comparing the effectiveness of physical and behavioural modelling with no intervention among non-sick-listed male railroad workers. ${ }^{11}$ However, we are not aware of other previous RCTs that have evaluated the effectiveness of multidisciplinary or graded activity interventions among non-sick-listed workers in the $\mathrm{OH}$ setting. 
At the time of designing the present study, a Cochrane systematic review ${ }^{12}$ recommended at least $100 \mathrm{~h}$ of multidisciplinary rehabilitation for chronic LBP. On the other hand, there was also evidence supporting the use of graded activity or other exercise programmes ${ }^{13} 14$ for LBP. Moreover, it was already recognised that carefully selected and presented information and advice about LBP can have a positive effect on patients' beliefs and clinical outcomes. ${ }^{15}$

In the present pragmatic trial we analysed the effectiveness of two active secondary prevention interventions (hospital outpatient rehabilitation and progressive back exercises, i.e., a graded exercise programme) compared to self-care advice. Our study was implemented in the occupational setting and self-care advice was provided by an occupational physician (OP). Primary outcomes were pain, physical impairment and health-related quality of life (HRQoL) at 2-year follow-up, and sickness absence (SA) over a 4-year follow-up.

\section{METHODS}

\section{Study design and ethics}

This was a longitudinal cohort study with two embedded RCTs. All employees in a forestry company were invited to respond to a postal questionnaire on LBP and back-related physical impairment. Based on the responses, the employees were divided into three main categories: 'no' low back (LB) symptoms, 'some' LB symptoms and 'LB symptoms potentially hampering work'. Two RCTs were performed in the subjects with some LB symptoms and with LB symptoms potentially hampering work, respectively. The present study describes the results of a trial with three arms after screening for employees with LB symptoms potentially hampering work. The South Karelian Central Hospital Research Ethics Board approved the study, and it was performed according to the Declaration of Helsinki.

\section{Participants}

The study was performed within one forestry company production unit in the city of Lappeenranta, Finland. The production unit includes a chemical mill, a pulp mill, a paper mill, a plywood mill, a saw mill and a planing plant. A structured questionnaire on LBP and related items was sent to the entire workforce $(n=2480)$ listed in the company registers in September 2001

The mean (SD) age of the 1754 respondents (71\% response rate) was 45 years (18-64 years), 70\% were blue-collar workers and $28 \%$ were female. Some $20 \%$ reported heavy, $36 \%$ moderate and $44 \%$ light work strain.

Inclusion criteria were age, presence of LBP and pain intensity. Based on the responses to the screening questionnaire, a group of 193 employees under the age of 57 were identified as having LBP symptoms 'potentially hampering work'. They had to fulfil at least one of the following criteria:

1. LBP lasting 2 weeks or more in the past 12 months

2. Radiating LBP at the time of responding to the questionnaire

3. Recurrent LBP (two or more episodes irrespective of their duration during the past 12 months)

4. Self-reported work absence because of LBP during the past 12 months.

In addition, they had to report an LBP intensity of $35 \mathrm{~mm}$ or more on a $100 \mathrm{~mm}$ visual analogue scale (VAS) during the past week.

Of these 193 employees, a random sample of 50 individuals formed a control group representing the natural course of LBP without any intervention. Data for the natural course group are not given in this paper.
The remaining 143 employees with LBP were invited to visit an $\mathrm{OP}$ (the first author) for a clinical examination. Exclusion criteria for the study were retirement, pregnancy, presence of acute nerve root entrapment, suspicion of malignancy, recent fracture, severe osteoporosis or other specific diseases preventing participation in the follow-up.

The study design, implications of the trial and alternative options were explained in the informed consent form, which emphasised that taking part in the trial was voluntary: employees would still get the best treatment and the full attention of the OP even if they did not participate and participants were free to withdraw from the trial at any point, and it would not prejudice their treatment.

Of the eligible subjects, 17 refused to participate. As none were excluded due to exclusion criteria, the remaining 126 subjects formed the study group for randomisation. The intervention groups were comparable regarding most basic characteristics (table 1 ).

\section{Randomisation and blinding}

An independent biostatistician prepared the randomisation scheme using a computer-generated randomisation table. To prevent unequal randomisation of subjects by age and gender in the treatment arms, scripted four-digit identification codes (ID) were sorted by gender and age ( $\leq 45$ years, $>45$ years), resulting in four strata. Block randomisation (with blocks of 15) was applied to ensure equal group sizes within each stratum. Based on the randomisation scheme, before the start of the study a research assistant prepared sealed envelopes containing either a referral to the outpatient rehabilitation at the hospital group, the progressive back exercise group or the self-care advice group. After signing the informed consent form, each employee opened a sealed envelope. The research personnel were not able to identify the IDs or the group assignments before randomisation. Due to the nature of the interventions, the participants and $\mathrm{OH}$ professionals were not blinded for the group assignment after randomisation. SA data were extracted from the electronic records of the $\mathrm{OH}$ services and self-reported data were entered into the computer by a research assistant, which ensured blinded analysis of the data by the researchers.

\section{Interventions}

All subjects had access to $\mathrm{OH}$ care as usual during the study period. At the first study visit to the OP, subjects were randomised into the intervention groups (described below) and all received information about $\mathrm{LBP}$, the trial and the follow-up.

Information about the study was also provided regularly in the company magazine and intranet; at the time of the study, no other specific $\mathrm{OH}$ or other health interventions were being carried out in the company. The $\mathrm{OH}$ unit of the company operated as usual during the study period.

Outpatient rehabilitation at the hospital physical medicine unit (PMU) Intensive, bio-psychosocial and multidisciplinary LBP rehabilitation was carried out at the physical medicine outpatient unit of the South Karelian Central Hospital in the city of Lappeenranta, Finland. ${ }^{16}$ The rehabilitation team consisted of a specialist doctor in physical medicine and rehabilitation, a psychologist, a social worker and several physiotherapists. The program included a 3 -week pre-course of $1.5 \mathrm{~h}$ light mobilisation and exercise sessions for 3 days each week, followed by an intensive 3 -week course that included progressive exercises and multidisciplinary information about LB syndrome and pain management. The rehabilitation program lasted for $6.5 \mathrm{~h}$ each day for 
Table 1 Baseline characteristics of study subjects

\begin{tabular}{|c|c|c|c|}
\hline Characteristics & $\begin{array}{l}\text { PMU } \\
(n=43)\end{array}$ & $\begin{array}{l}\text { DBC } \\
(n=43)\end{array}$ & $\begin{array}{l}B B \\
(n=40)\end{array}$ \\
\hline \multicolumn{4}{|l|}{ Demographic features } \\
\hline Age, years & $45(9)$ & $44(8)$ & $45(7)$ \\
\hline Male, \% & 65 & 72 & 68 \\
\hline Married, \% & 81 & 84 & 70 \\
\hline Body mass index, $\mathrm{kg} / \mathrm{m}^{2}$ & 26 & 28 & 28 \\
\hline Smoking, \% & 31 & 40 & 40 \\
\hline High school diploma or vocational degree, \% & 67 & 56 & 58 \\
\hline \multicolumn{4}{|l|}{ General health } \\
\hline Self-rated health status moderate or better, \% & 95 & 88 & 95 \\
\hline Previous low back operation, $\%$ & 5 & 2 & 8 \\
\hline Duration of LBP, years & 13 & 10 & 14 \\
\hline $\begin{array}{l}\text { Previous rehabilitation for LBP or active } \\
\text { self-care, \% }\end{array}$ & 28 & 35 & 35 \\
\hline $\begin{array}{l}\text { Medical history of chronic morbidity } \\
\text { other than LBP, \% }\end{array}$ & 33 & 30 & 30 \\
\hline $\begin{array}{l}\text { Physical activity twice or more/week } \\
\text { before LBP, \% }\end{array}$ & 77 & 65 & 68 \\
\hline \multicolumn{4}{|l|}{ Work related features } \\
\hline Blue collar, \% & 74 & 77 & 90 \\
\hline Shift work, \%† & 43 & 28 & 39 \\
\hline Physical work load $(1-5) \ddagger$ & $3.2(1.0)$ & $3.1(0.8)$ & $2.7(0.8)$ \\
\hline Mental work load $(1-5) \neq$ & $2.5(0.9)$ & $2.8(0.8)$ & $2.9(0.8)$ \\
\hline Work ability $(0-10) \S$ & $6.8(2.0)$ & $7.1(1.7)$ & $6.8(2.4)$ \\
\hline At least some or more work control, \% & 65 & 72 & 68 \\
\hline Total sickness absence days in previous year* & 16 & 21 & 19 \\
\hline \multicolumn{4}{|l|}{ Screening criteria } \\
\hline Intensity of pain in past week (VAS, $0-100$ ) & 60 & 55 & 60 \\
\hline LBP radiating below the knee, $\%$ & 51 & 51 & 45 \\
\hline $\begin{array}{l}\text { Subacute LBP for } 2 \text { weeks or more in previous } \\
\text { year, \% }\end{array}$ & 56 & 44 & 53 \\
\hline Recurrent LBP (more than once/year), \% & 86 & 95 & 93 \\
\hline $\begin{array}{l}\text { Self-reported LBP work absence in } \\
\text { previous year, \% }\end{array}$ & 33 & 37 & 40 \\
\hline \multicolumn{4}{|l|}{ Outcome variable at randomisation } \\
\hline Intensity of pain (past week) (VAS, 0-100 mm) & $43(23)$ & $39(24)$ & $34(25)$ \\
\hline Physical impairment (RM-18, 0-18) & $8(5)$ & $6(5)$ & $6(5)$ \\
\hline Disability (ODI, 0-100), \% & $21(13)$ & $17(12)$ & $16(11)$ \\
\hline Fear of pain $(\mathrm{FABO}, 13-78)$ & $37(14)$ & $35(11)$ & $32(12)$ \\
\hline Depression (DEPS, 0-30) & $6(4)$ & $4(5)$ & $4(4.0)$ \\
\hline HROoL score $(15 D, 0-1)$ & 0.8681 & 0.8884 & 0.8932 \\
\hline
\end{tabular}

Values are mean (SD) unless otherwise stated. Range (when applicable) is presented after the variable name in parenthesis.

*Register data.

†Two-shift or three-shift work.

‡Range $1-5$ indicates self-rated load level: $1=$ very heavy, $2=$ moderate, $3=$ intermediate, $4=$ rather light, $5=$ very light.

§Range $0-10$, where 0 is the is the lowest possible work ability and 10 is the best possible work ability.

$\mathrm{BB}$, Back Book intervention group; DBC, progressive back specific exercises group; HROoL, health related quality of life; LBP, low back pain; PMU, hospital physical medicine unit

group; VAS, visual analogue scale.

5 days each week, that is 15 days altogether. Finally, a personal maintenance exercise program was designed for the subjects and they were later invited to a follow-up visit within 6 months of the initial course. The subjects were not sick-listed during the 3 -week intensive period, but were effectively out of work and received compensation from the Social Insurance Institution of Finland. The costs of the course were covered by the public health care budget. Outpatient rehabilitation at a hospital PMU is a widely used method to treat persistent LBP in Finland.

Progressive back specific exercises (DBC)

A graded activity program was carried out in a physiotherapy outpatient clinic. ${ }^{13} 17$ It consisted of a $1 \mathrm{~h}$ session twice or three times a week, over a period of 12 weeks, supervised by a specially trained physiotherapist. The treatment included exercises targeted at the trunk muscles using specific equipment together with stretching and relaxation. The physiotherapists emphasised the 'good prognosis' for LBP during the treatment sessions and the subjects were instructed in performing LB exercises at home. The importance of home exercises was emphasised during the exercises.

\section{Self-care advice by an OP based on the Back Book (BB)}

During the visit to the $\mathrm{OP}$, the findings of the clinical examination were explained to the subject. The employee was given a copy of the Back Book ${ }^{15}$ and the OP explained the contents of the booklet, emphasising the benign nature of and good prognosis for LBP. The Back Book focuses on patients' beliefs and pain management and encourages staying active in spite of LBP. The booklet also offers practical advice for patients suffering from an acute or subacute LBP episode. We implemented the self-care advice as a low-cost control intervention.

\section{Outcome measures and data collection}

After randomisation, participants were followed up for 24 months for the questionnaire data and for 48 months for the SA data.

\section{Primary outcome measures}

Pain intensity, physical impairment, HRQoL and SA days were the primary outcomes of this study. The follow-up questionnaires included the following previously validated and widely used items: intensity of LBP $\left(V^{\prime} S^{18}\right)$ during the preceding week, physical impairment measured using the Roland-Morris 18-item scale $(\mathrm{RM}-18)^{19}$ and Health related quality of life, HRQoL (15D). ${ }^{20}$

SA data were obtained from the electronic medical records of the $\mathrm{OH}$ services. Records were carefully checked for inconsistencies and maternity or paternity leave and absence to care for a sick child were not included. SA days were analysed in two ways, according to (1) LBP specific SA days with no time limit or (2) any (=total) SA days, that is the sum of 'LB specific' and 'other' SA days. Among non-LB specific SAs, periods longer than 30 days were omitted from the category in order to prevent severe diseases and the consequences of injury confounding the analyses. The cut-off limit of 30 days per SA period was chosen arbitrarily before conducting any analyses.

\section{Secondary outcome measures}

Disability (ODI, Oswestry Disability Index), ${ }^{21}$ depressive symptoms (Depression Scale, DEPS), ${ }^{22}$ fear avoidance (FearAvoidance Beliefs Questionnaire, FABQ $)^{23}$ and SA periods were the secondary outcomes of this study. ODI, DEPS and FABO scores were collected from the follow-up questionnaires. The data for the SA periods were calculated in the same way as for the SA days above (see 'Primary outcome measures' section).

\section{Power calculations}

A power calculation for the difference in LBP intensity (VAS) was carried out. The SD was expected to be 15 units ( $\mathrm{mm}$ ). Calculations showed that differences in LBP intensity of $10 \mathrm{~mm}$ between groups would be detectable with $80 \%$ power in twotailed tests with a significance level of 0.05 for a sample of 40 employees in each group.

\section{Statistical analyses}

All statistical analyses were performed at employee level, according to the intention-to-treat principle. Missing 
questionnaire data were imputed using the last observation carried forward principle. Baseline characteristics were compared using descriptive statistics. The effectiveness of the interventions was primarily estimated by the difference in the outcome variables between the two active interventions and the control group (PMU vs BB; $\mathrm{DBC}$ vs $\mathrm{BB}$ ) at 3, 6, 12 and 24 months for the questionnaire variables and at 12, 24, 36 and 48 months for the SAs. The $95 \%$ CIs for the mean differences between groups were computed using the generalised linear model where the respective baseline values were used as covariates (when appropriate). We used the statistical package SPSS 17.0 for Windows. ${ }^{23}$

As regards the SA variables, we tested different observational models and hierarchical latent regression models. Count data are commonly modelled using Poisson, negative binomial and corresponding zero inflated models. For all SA variables there was great overdispersion in relation the Poisson model and an excess of zeros in relation to the non-inflated models. We therefore used a two-component hurdle model ${ }^{24}$ where the first process determines whether a person has any SAs and the second determines the number of SA periods or days. In the zero component, the latent function models the logit of the probability that SA days or periods are larger than zero. In the count component, the latent function models the log of the mean parameter of the zero truncated negative binomial. We tested both linear and non-linear models with different hierarchical structures. The final choice for both latent models was a hierarchical Gaussian process model with a neural network covariance function. ${ }^{25} 26$ The constructed hierarchical model ${ }^{27}$ included a common effect, an effect for the baseline, effects for each intervention group and effects for each person (also called 'random effects'). For the logistic model, we report the probabilities of SAs and the odds ratios. For the zero truncated negative binomial model, we report mean SA days or periods and mean ratios. The Gaussian process models were implemented using the GPstuff toolbox (http://www.lce.hut.fi/research/mm/ gpstuff/). ${ }^{26}$ Additional details are provided in the online statistical appendix.

\section{RESULTS \\ Employee flow}

Figure 1 shows the flow of participants in this trial. A total of 126 employees were randomised to outpatient rehabilitation at the hospital (PMU, $\mathrm{n}=43$ ), progressive back specific exercises (DBC, $n=43)$ or self-care advice $(B B, n=40)$.

\section{Primary outcomes}

The results are shown in table 2 .

\section{Pain and physical impairment}

At 3 and 6 months, PMU was more effective compared to $\mathrm{BB}$ regarding pain (mean difference $(\mathrm{MD})$ at 3 months: $-10 \mathrm{~mm}(95 \%$ $\mathrm{CI}-19$ to -1$)$; $\mathrm{MD}$ at 6 months: $-10 \mathrm{~mm}(95 \% \mathrm{CI}-20$ to -1$)$ ), but was no longer effective at 12 months (MD: $-7 \mathrm{~mm}(95 \%$ CI -21 to 2$)$ ).

At 3 months, $\mathrm{MD}$ for $\mathrm{DBC}$ versus $\mathrm{BB}$ regarding pain was $-6 \mathrm{~mm}(95 \% \mathrm{CI}-16$ to 3$)$ and at 6 months $-4 \mathrm{~mm}(95 \%$ $\mathrm{CI}-14$ to 5$)$. At 12 months, $\mathrm{DBC}$ was more effective regarding pain (MD for DBC vs BB $-12 \mathrm{~mm}(95 \% \mathrm{CI}-21$ to -2$))$ than $\mathrm{BB}$.

The active interventions were not effective in reducing physical impairment (RM-18) during follow-up from 3 to 24 months compared to self-care advice (MDs at 3 months: $\mathrm{PMU}$ vs $\mathrm{BB}-1$ ( $95 \%$ CI -2 to 1$)$; DBC vs BB $0(95 \%$ CI -1 to 2$)$ ).

At 24 months, no relevant differences were seen between the treatment arms regarding pain (MDs for PMU vs $\mathrm{BB}-5 \mathrm{~mm}$
(95\% CI -13 to 4$)$; $\mathrm{DBC}$ vs $\mathrm{BB}-5 \mathrm{~mm}(95 \% \mathrm{CI}-13$ to 4$))$ or $\mathrm{MD}$ regarding physical impairment (PMU vs $\mathrm{BB}-1$ (95\% CI -3 to 0$)$; $\mathrm{DBC}$ vs $\mathrm{BB}-1(95 \% \mathrm{CI}-3$ to 1$))$.

\section{HRQOL}

HRQoL (15D) improved in the DBC group towards the end of the follow-up period (MDs of DBC vs BB were 0.03 (95\% CI 0.00 to 0.05 ) at 12 and 24 months).

\section{Sickness absence}

The results are shown in figures 2 and 3 .

The MD between PMU and BB in total SA days over 4 years was -41 (95\% CI -93 to 8). In comparison to BB, PMU reduced the probability of total SA during the first (OR $0.34(95 \% \mathrm{CI}$ 0.14 to 0.81$)$ ) and second (OR 0.41 (95\% CI 0.19 to 0.88$)$ ) follow-up years (figure $2 \mathrm{~B}$ ). Among those who had had any $\mathrm{SA}$, the number of SA days was lower in PMU than BB during the fourth year (mean ratio (MR) 0.53 (95\% CI 0.31 to 0.92 )) (figure 2D).

The $\mathrm{MD}$ between $\mathrm{DBC}$ and $\mathrm{BB}$ in total SA days over 4 years was -17 (95\% CI -70 to 35$)$. No difference in the probability or total number of SA days was found between DBC and $\mathrm{BB}$ (figure 2).

The $\mathrm{MD}$ between $\mathrm{DBC}$ and $\mathrm{BB}$ in $\mathrm{LBP}$ specific SA days over 4 years was -15 (95\% CI -47 to 13$)$. In comparison to $\mathrm{BB}, \mathrm{DBC}$ reduced the probability of $L B P$ specific SA during the third (OR 0.24 (95\% CI 0.07 to 0.81$)$ ) and fourth (OR 0.16 (95\% CI 0.04 to $0.62)$ ) follow-up years (figure $3 \mathrm{~B}$ ). Among those who had had any LBP specific SA, no difference was found in the number of LBP specific SA days between DBC and BB (MRs from 0.78 to 1.42).

The $\mathrm{MD}$ between $\mathrm{PMU}$ and $\mathrm{BB}$ regarding $\mathrm{LBP}$ specific SA days over 4 years was $5(95 \% \mathrm{CI}-30$ to 47$)$. No difference in the probability or the number of LB specific SA days was found between PMU and BB (figure 3).

\section{Secondary outcomes}

\section{Questionnaire variables}

The results are presented in table 2 .

Disability (ODI) was lower in the PMU group compared to the $\mathrm{BB}$ group at 3 and 24 months (3 months: $-4 \%$ (95\% CI $-8 \%$ to $0 \%) ; 24$ months: $-5 \%$ (95\% CI $-10 \%$ to $-1 \%)$ ).

Pain related fear (FABQ) was lower in both active treatment arms compared to self-care information towards the end of the 24-month follow-up period.

Depression score (DEPS) was lower in the DBC group at 24 months compared to the BB group ( -2 (95\% CI -4 to 0$)$ ).

\section{Sickness absence (SA) periods}

Among those who had had any SA, PMU reduced the number of SA periods during the third (MR 0.6 (95\% CI 0.41 to 0.89 )) and fourth (MR 0.44 (95\% CI 0.27 to 0.71$)$ ) years in comparison to $\mathrm{BB}$ (figure $2 \mathrm{~F}$ ). No such difference was found between $\mathrm{DBC}$ and $\mathrm{BB}$.

Among those who had had any LB specific SA, no difference was found in the number of SA periods between either of the active interventions and $\mathrm{BB}$ (figure $\mathrm{BF}$ ).

\section{Adverse effects}

No adverse events were reported during the interventions.

\section{DISCUSSION \\ Main findings}

Progressive back specific exercises improved HRQoL at the 12 month and 24-month follow-up time points, reduced the probability of LB specific SA during the third and fourth follow-up 
Figure 1 Flow diagram of the course of the study showing the number of subjects at different phases of the trial. $\mathrm{BB}$, Back Book intervention group; DBC, progressive back specific exercises group; PMU, hospital physical medicine unit group.

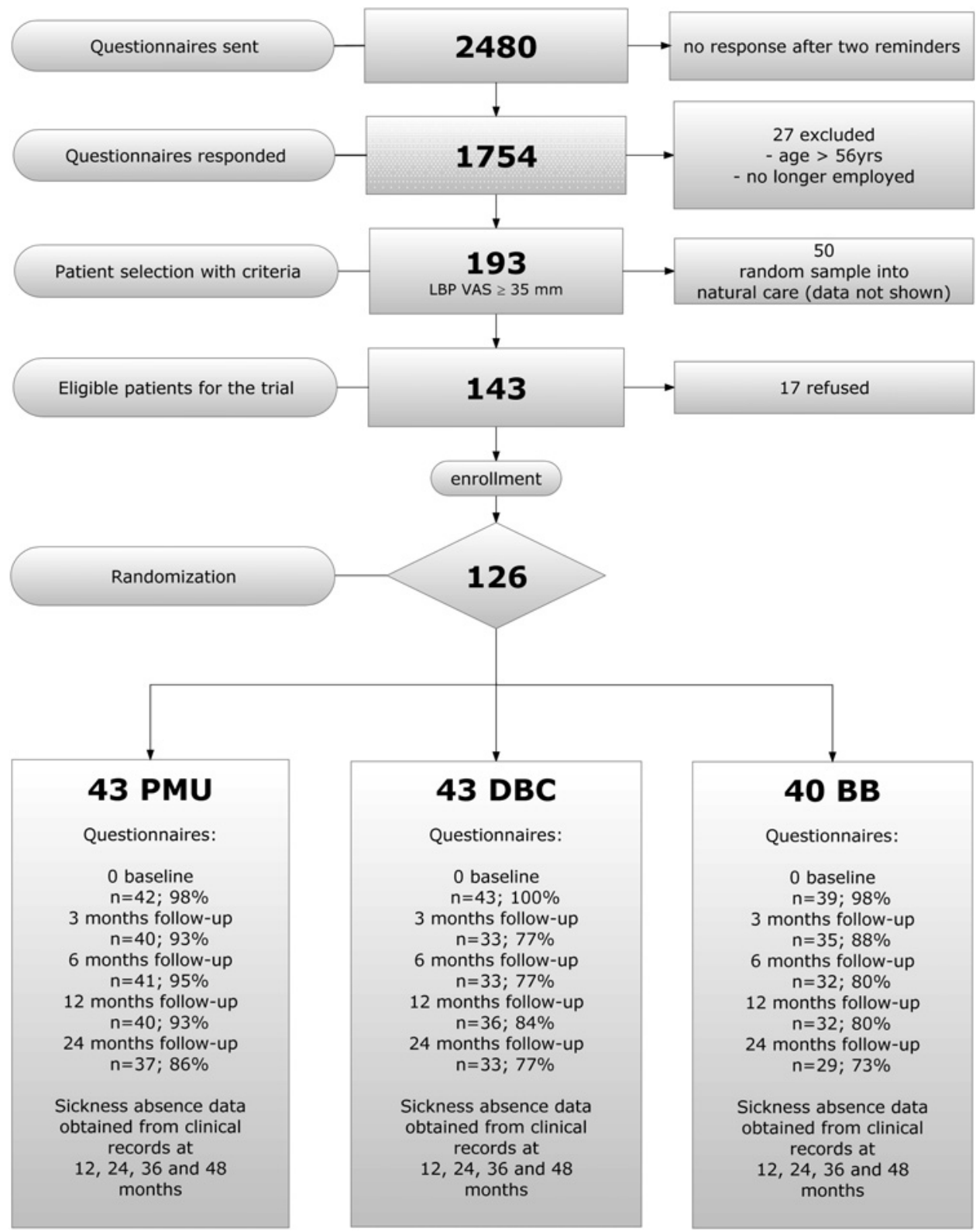

years, and were more effective for pain than self-care at 12 months. Outpatient rehabilitation at the hospital reduced the probability of any SA days during the first 2 years, reduced the number of SA days in the fourth year, the number of SA periods in the third and fourth year and was more effective for pain at 3 and 6 months than self-care advice. Disability and pain related fear decreased in both active groups and depression in the Progressive back exercises group, as compared to self-care information over 2 years.

The effect sizes were rather small, which is partly explained by the low baseline levels of the outcome variables in our trial.

\section{Strengths and weaknesses of the study}

The main strength of the study lies in the pragmatic approach of this RCT. All permanent employees in the target cohort were initially offered the opportunity to participate in the questionnaire survey. The response rate was reasonably high at $71 \%$. Selection of eligible employees for the trial was based on straightforward criteria: LBP frequency, duration and intensity of pain and self-reported SA due to LBP. Our intention was to include subjects who had periodic or chronic LBP potentially hampering work but not yet preventing it. The study population was somewhat heterogeneous concerning LBP severity, although symptoms were generally mild.

Only $17(12 \%)$ of the 143 eligible participants refused to take part. Randomisation was successful and the treatment arms were comparable regarding the relevant demographic factors.

The employees' own OP carried out the baseline clinical examination and provided advice about the self-care intervention. Adherence to the trial was reasonably high, although loss to follow-up was somewhat unequal between the treatment arms (figure 1). All interventions were based on existing clinical practice, and experimental methodologies were not introduced We selected a representative sample of some $10-15 \%$ of the employees with the most severe LB symptoms in the cohort; however, most participants in our study had only relatively mild symptoms.

The questionnaire variables were based on previously validated and widely used techniques but have been primarily used in patients with more severe symptoms. 
Table 2 Results of primary and secondary outcomes (questionnaire variables) and comparisons between the active intervention groups and the control group (BB) at the 2-year follow-up

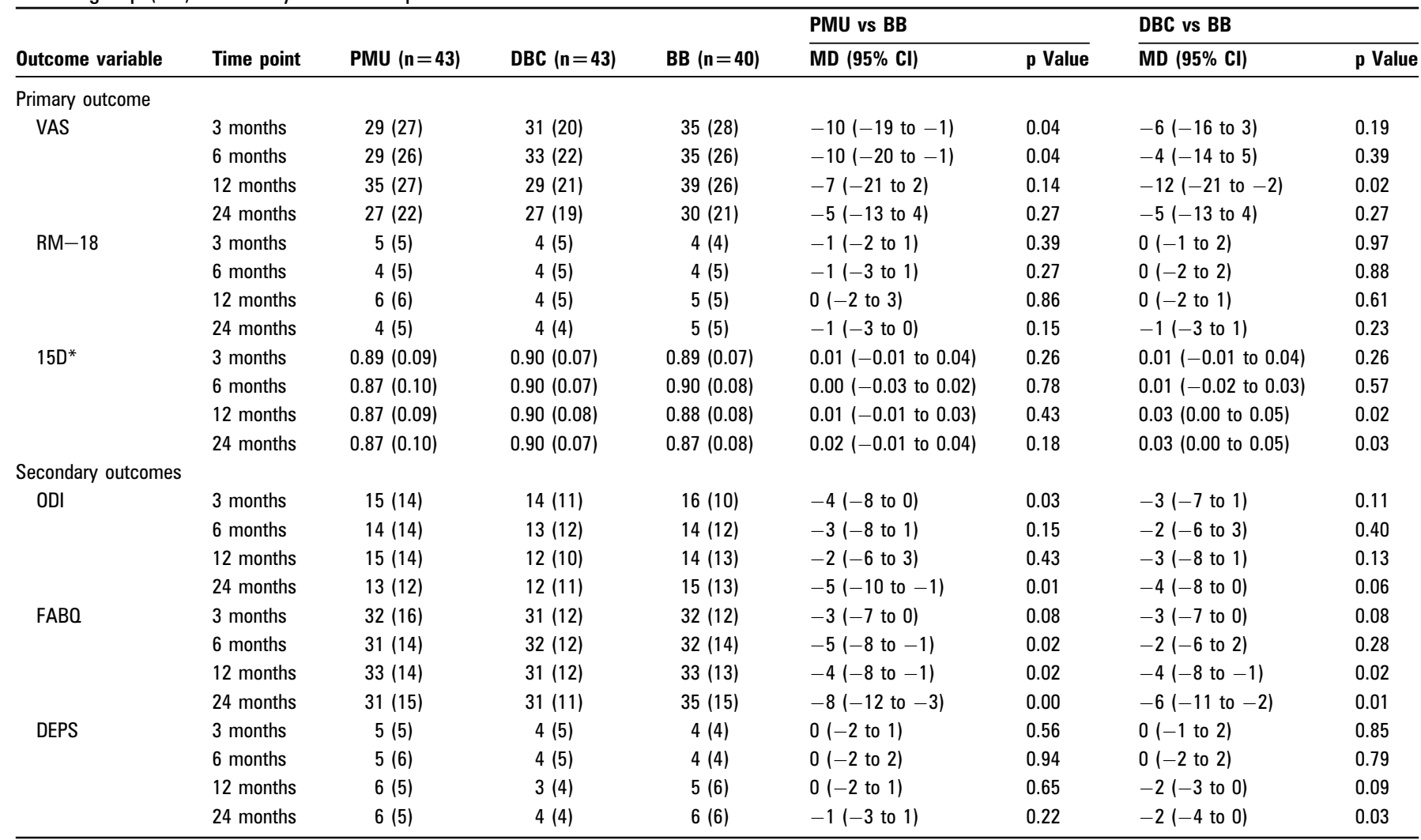

Mean (SD), mean difference (MD) and $95 \% \mathrm{Cl}$, and $\mathrm{p}$ value for the $\mathrm{MD}$.

*HROoL, Range $0-1$; higher values indicate better quality of life.

DEPS, Depression Scale; FABQ, Fear-Avoidance Beliefs Questionnaire; ODI, Oswestry Disability Index; RM-18, Roland-Morris Disability Scale; VAS, visual analogue scale; 15D, 15 Dimensional Quality of Life.

One of the primary outcomes was based on recorded SAs. This has several advantages: good coverage, accuracy and consistency. $^{28}$ As salaries and other employee benefits in this company are based on the same absence data that we used in our study, SA records are very accurate and consistent. However, the fact that our study is somewhat underpowered as regards SA variables can, for example, be seen from the broad confidence intervals in the differences between the treatment arms.

During the study follow-up period (2002-2005), the number of LB specific SA was stable or slowly increasing at the national level in Finland. ${ }^{29}$ At the same time, according to company registers, the total SA rate remained stable at approximately $5-5.5 \%$ of the theoretical working hours per year. There were no major job losses or other threats facing personnel or the financial performance of the company during the study follow-up period. The turmoil that affected the entire Finnish forestry industry effectively started shortly after our data collection ended. Nevertheless, any potential external confounding factors would have influenced the treatment arms equally.

\section{Some differences compared with previous studies}

The majority of previous RCTs in $\mathrm{OH}$ settings concerning LBP have been performed with selected groups of employees already on sick leave. In a Finnish RCT, male railroad employees with LBP were invited into a trial on the basis of $\mathrm{OH}$ registers. ${ }^{11}$ The subjects were randomised into physical training or usual care. The baseline pain and disability levels were even lower than in our study. The main results were a slight decrease in pain at 12 months and an increase in subjective future work ability. ${ }^{11}$ The inclusion criteria in that study were somewhat comparable to those in our study, and the results in both studies indicate some effectiveness of active interventions regarding symptoms in moderately symptomatic subjects.

In a 12-month follow-up study, a graded activity intervention (comparable to DBC in our study) improved the return to work rate but was ineffective in improving functional status or reducing pain among workers who had been on full or partial sick leave because of LBP for at least 4 weeks prior to inclusion in the study. ${ }^{7}$ There was a substantial reduction in the total number of sick leave days compared to the usual care group, but the difference was statistically insignificant. The authors suggest that this may be because the trial was underpowered for the inherently skewed nature of length of sick leave distributions or cost savings. ${ }^{5}$ In another study with a 6-month follow-up, a low-intensity back school was more effective in reducing work absence than a high-intensity back school or usual care, among workers sick-listed due to subacute LBP. ${ }^{30}$ The effects of treatment on functional status and kinesiophobia were borderline significant, a result which also favours low-intensity intervention. Pain relief did not differ between the groups. Some previous studies have shown the effectiveness of a coordinated returnto-work programme for sick-listed employees with LBP. ${ }^{6} 31$ However, as these programmes also include a workplace intervention for employees already sick-listed, they are not directly comparable with our study.

Numerous other studies ${ }^{31-37}$ and a Cochrane review ${ }^{38}$ on the (secondary) prevention of LBP with various designs and settings other than $\mathrm{OH}$ have resulted in decreases in pain, fewer recurrent $\mathrm{LB}$ episodes, less disability, etc, after physical activity, psycho-educational or multidisciplinary interventions or combinations of these. 
Figure 2 Total sickness absence (SA) by years: a hurdle model where the first (logistic) component determines whether a person has any SA and the second (zero truncated Negbin) component determines the total number of SA days or periods over the 4-year follow-up period. (A) Probability and $95 \% \mathrm{Cl}$ of any SA by groups; (B) comparisons of the probability of any SA between the intervention groups (PMU and $\mathrm{DBC})$ and the control group (BB) (OR and $95 \% \mathrm{Cl})$; (C) total number of $S A$ days by groups (mean and $95 \%$ CI); (D) comparisons of the total number of SA days between the intervention groups and the control group (mean ratio with $95 \% \mathrm{CI}$ ); (E) total number of SA periods by groups (mean and 95\% $\mathrm{Cl}$ ); $(\mathrm{F})$ comparisons of the total number of SA periods between the intervention groups and the control group (mean ratio with $95 \% \mathrm{CI}$ ). BB, Back Book intervention group; $\mathrm{DBC}$, progressive back specific exercises group; PMU, hospital physical medicine unit group.
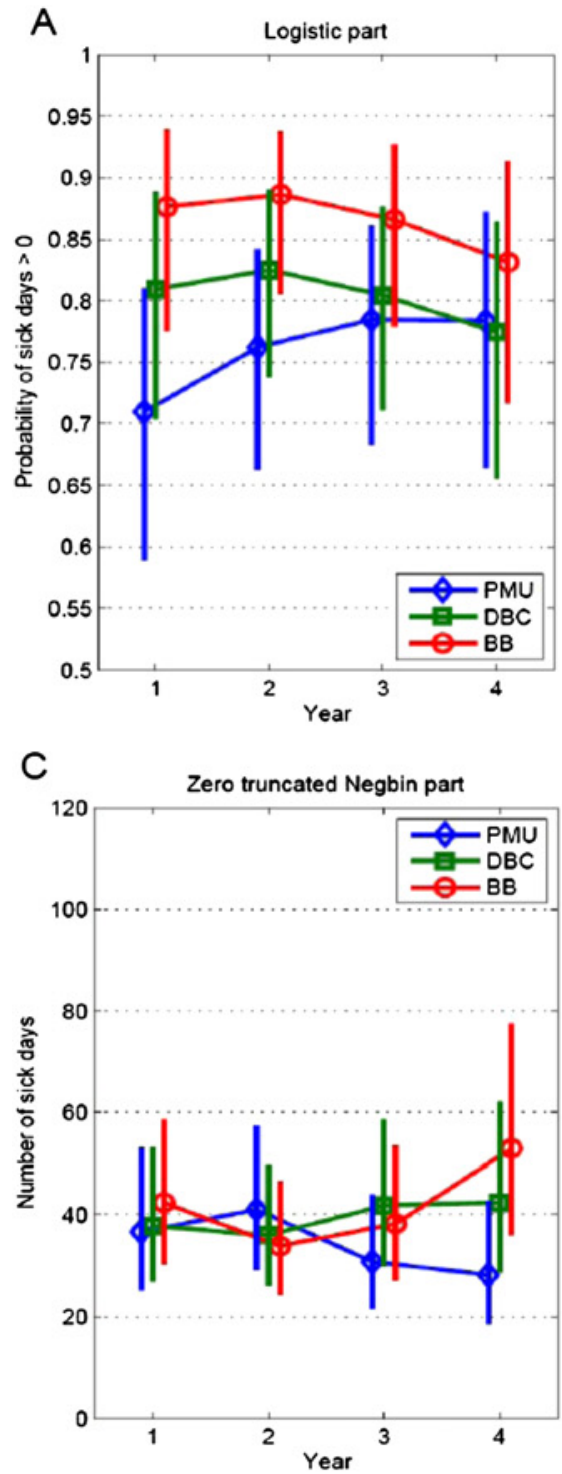

E

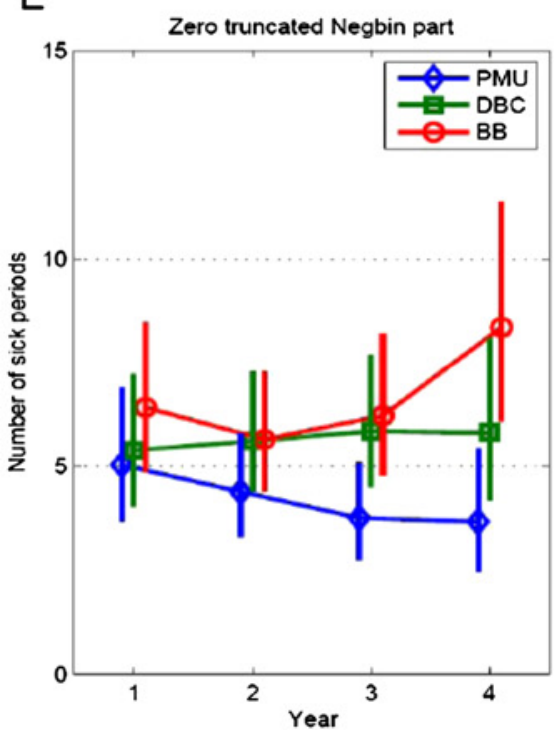

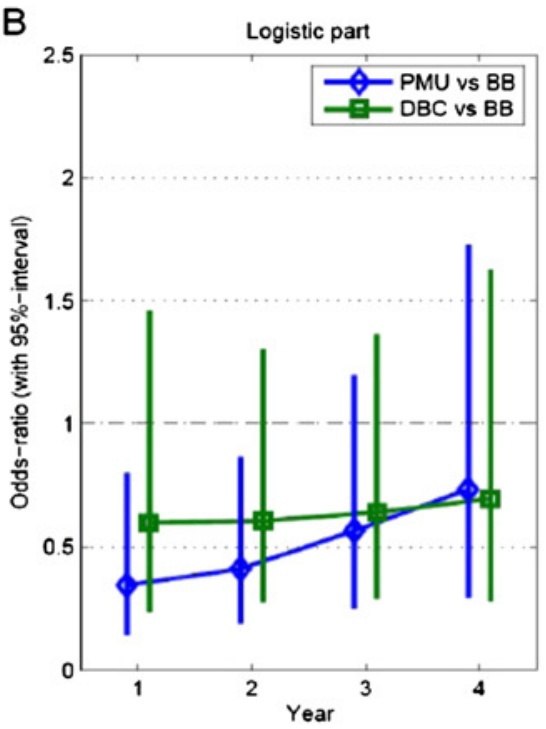

D

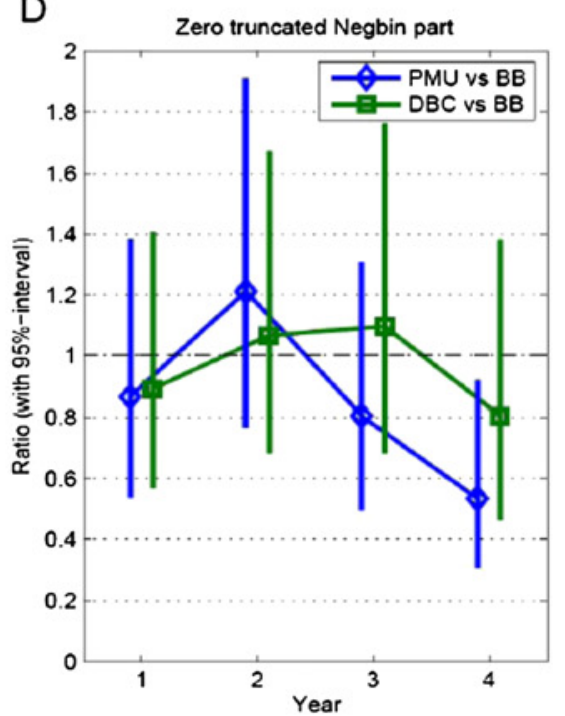

F

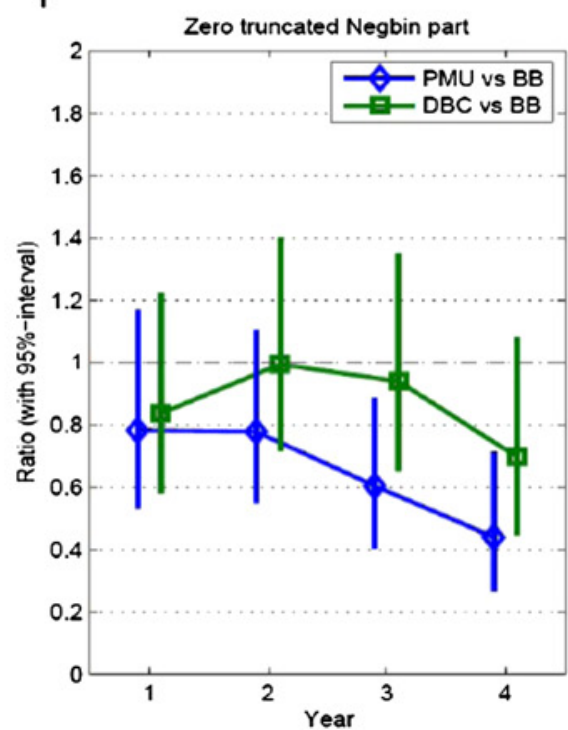

In a recently published $\mathrm{RCT}$, a targeted $\mathrm{OH}$ intervention was found to be effective regarding SA among workers at high risk of SA, defined by self-rated symptoms irrespective of baseline
SA, when compared to usual care. ${ }^{39}$ The targeted $\mathrm{OH}$ intervention was also cheaper. ${ }^{40}$ Exploratory analyses in the trial indicated that the targeted intervention was especially effective for those 
Figure 3 Low back pain (LBP) specific sickness absence (SA) by years:

a hurdle model where the first (logistic) component determines whether a person has any LBP specific SA and the second (zero truncated Negbin) component determines the number of LBP specific SA days or periods over the 4-year follow-up period. (A) Probability and $95 \% \mathrm{Cl}$ of LBP specific $S A$ by groups; (B) comparisons of the probability of LBP specific SA between the intervention groups (PMU and $\mathrm{DBC}$ ) and the control group (BB) (OR and $95 \%$ $\mathrm{CI})$; (C) number of LBP specific SA days by groups (mean and $95 \% \mathrm{CI}$ ); (D) comparisons of the number of LBP specific SA days between the intervention groups and the control group (mean ratio with $95 \% \mathrm{Cl}$ ); (E) number of LBP specific SA periods by groups (mean and $95 \% \mathrm{CI}$ ); $(\mathrm{F})$ comparisons of the number of LBP specific SA periods between the intervention groups and the control group (mean ratio with $95 \% \mathrm{Cl}$ ). $\mathrm{BB}$, Back Book intervention group; DBC, progressive back specific exercises group; PMU, hospital physical medicine unit group.
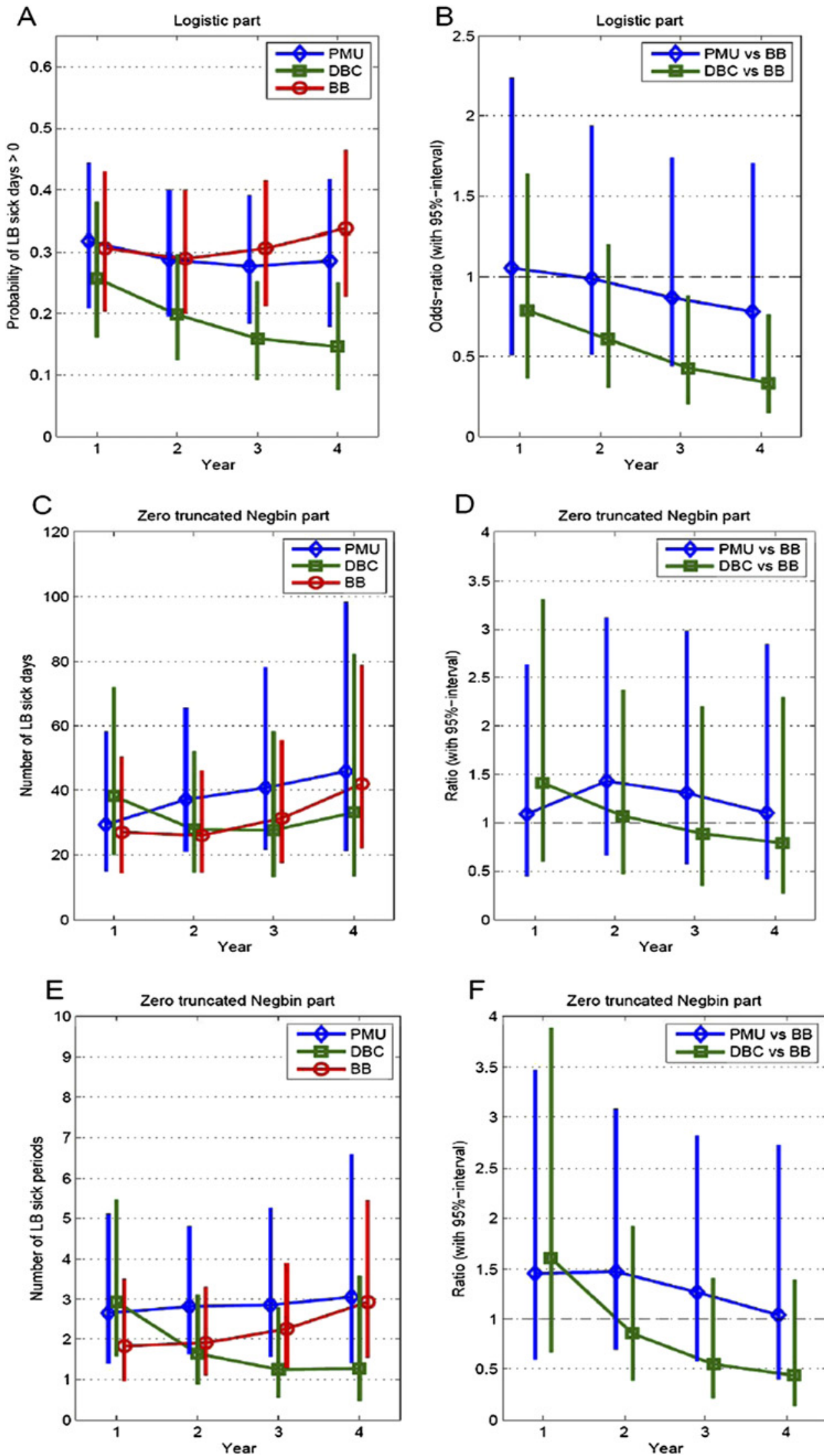

workers who were certain that they would be unable to continue working in their current job for health reasons and had comorbidities or severe physical impairment at work. ${ }^{41}$

In summary, only a few RCTs in the $\mathrm{OH}$ setting have attempted to identify non-sick-listed employees at risk of LBP- related disability and then set up an intervention for these individuals. These studies all show some effectiveness, but the effect sizes have been rather small. The optimal strategies for secondary prevention of LBP related disability need to be determined. 


\section{Conclusions and implications for future trials}

Two active interventions focused on non-sick-listed employees selected from their workplace, resulted in improved HRQoL and less LBP, disability and pain related fear. However, the small decrease in pain was not sustained over the 2-year follow-up period, the borderline improvement in quality of life was only realised after 1-year of follow-up and the effects on SA were minor. The small decrease in the probability and number of any SA days with multidisciplinary rehabilitation at the hospital was not reflected in LB specific sick leave. Although the included subjects were drawn from among the $10 \%$ most symptomatic respondents, they still experienced relatively mild LB symptoms. One reason for the modest effect sizes may be related to the inclusion in the study of non-sick-listed employees with low baseline values.

Although outpatient rehabilitation at the hospital showed the best results in reducing SA, its cost-effectiveness must be further evaluated before it is recommended for widespread use in similar populations. Further research on this topic is warranted. In order to identify the most suitable subjects for secondary prevention, patient selection criteria and the optimal intervention strategy need to be determined.

Funding Centenary Foundation of Kymi Corporation, Yrjo Jahnsson Foundation, Juho Vainio Foundation and Finnish Cultural Foundation funded the research at the beginning of this study. The authors' work is independent of the funders.

Competing interests JR, SL, JK, AV and AM have no competing interests to declare. During physical medicine unit (PMU) interventions, MH was the head physician of the PMU. ST is the Medical Director of DBC International.

Ethics approval The South Karelian Central Hospital Research Ethics Board approved this study (record number (Dnr) A18/01).

Provenance and peer review Not commissioned; externally peer reviewed.

\section{REFERENCES}

1. Stanton TR, Latimer J, Maher CG, et al. Definitions of recurrence of an episode of low back pain: a systematic review. Spine (Phila Pa 1976) 2009;34:E316-22.

2. Staal JB, Hlobil H, Twisk JW, et al. Graded activity for low back pain in occupational health care: a randomized, controlled trial. Ann Intern Med 2004;140:77-84.

3. Anema JR, Steenstra IA, Bongers PM, et al. Multidisciplinary rehabilitation for subacute low back pain: graded activity or workplace intervention or both? A randomized controlled trial. Spine (Phila Pa 1976) 2007;32:291-8; discussion 299-300.

4. Loisel P, Abenhaim L, Durand P, et al. A population-based, randomized clinical trial on back pain management. Spine (Phila Pa 1976) 1997;22:2911-18.

5. Hobil H, Uegaki K, Staal JB, et al. Substantial sick-leave costs savings due to a graded activity intervention for workers with non-specific sub-acute low back pain. Eur Spine J 2007;16:919-24.

6. Lambeek LC, van Mechelen W, Knol DL, et al. Randomised controlled trial of integrated care to reduce disability from chronic low back pain in working and private life. BMJ 2010;340:c1035.

7. Hlobil H, Staal JB, Twisk J, et al. The effects of a graded activity intervention for low back pain in occupational health on sick leave, functional status and pain: 12-month results of a randomized controlled trial. J Occup Rehabil 2005;15:569-80.

8. Anema JR, Schellart AJ, Cassidy JD, et al. Can cross country differences in return-towork after chronic occupational back pain be explained? An exploratory analysis on disability policies in a six country cohort study. J Occup Rehabil 2009;19:419-26.

9. Lambeek LC, van Mechelen W, Buijs PC, et al. An integrated care program to prevent work disability due to chronic low back pain: a process evaluation within a randomized controlled trial. BMC Musculoskelet Disord 2009:10:147.

10. Loisel P, Lemaire J, Poitras $S$, et al. Cost-benefit and cost-effectiveness analysis of a disability prevention model for back pain management: a six year follow up study. Occup Environ Med 2002;59:807-15.

11. Suni J, Rinne M, Natri A, et al. Control of the lumbar neutral zone decreases low back pain and improves self-evaluated work ability: a 12-month randomized controlled study. Spine (Phila Pa 1976) 2006;31:E611-20.

12. Guzman J, Esmail R, Karjalainen K, et al. Multidisciplinary rehabilitation for chronic low back pain: systematic review. BMJ 2001;322:1511-16.

13. Kankaanpaa M, Taimela S, Airaksinen 0 , et al. The efficacy of active rehabilitation in chronic low back pain. Effect on pain intensity, self-experienced disability, and lumbar fatigability. Spine 1999;24:1034-42.
14. Lindstrom I, Ohlund C, Eek $\mathrm{C}$, et al. The effect of graded activity on patients with subacute low back pain: a randomized prospective clinical study with an operant-conditioning behavioral approach. Phys Ther 1992;72:279-90; discussion 291-3.

15. Burton AK, Waddell G, Tillotson KM, et al. Information and advice to patients with back pain can have a positive effect. A randomized controlled trial of a novel educational booklet in primary care. Spine 1999;24:2484-91.

16. Hupli M, Pylkkönen A. Akiivisen selkäkuntoutuksen toteutus ja laadunvalvonta erikoissairaanhoidossa (In Finnish). Suomen Lääkärilehti 1998:53:959.

17. Taimela S, Harkapaa K. Strength, mobility, their changes, and pain reduction in active functional restoration for chronic low back disorders. J Spinal Disord 1996:9:306-12.

18. Million R, Hall W, Nilsen $\mathrm{KH}$, et al. Assessment of the progress of the back-pain patient 1981 Volvo Award in Clinical Science. Spine 1982;7:204-12.

19. Stratford PW, Binkley JM. Measurement properties of the RM-18. A modified version of the Roland- Morris Disability Scale. Spine 1997;22:2416-21.

20. Sintonen H. The $15 D$ instrument of health-related quality of life: properties and applications. Ann Med 2001;33:328-36.

21. Fairbank JC, Couper J, Davies JB, et al. The Oswestry low back pain disability questionnaire. Physiotherapy 1980;66:271-3.

22. Salokangas RK, Poutanen 0, Stengard E. Screening for depression in primary care. Development and validation of the Depression Scale, a screening instrument for depression. Acta Psychiatr Scand 1995;92:10-16.

23. Waddell G, Newton M, Henderson I, et al. A Fear-Avoidance Beliefs Questionnaire (FABO) and the role of fear-avoidance beliefs in chronic low back pain and disability. Pain 1993:52:157-68.

24. Mullahy J. Specification and testing of some modified count data models. J Econometrics 1986;33:341-65.

25. Rasmussen CE, Williams CKI. Gaussian Processes for Machine Learning. Cambridge, MA, USA: The MIT Press, 2006.

26. Vanhatalo J, Riihimäki J, Hartikainen J, et al. Bayesian modeling with Gaussian processes using the MATLAB toolbox GPstuff. Submitted 2011.

27. Gelman A, Hill J. Data Analysis Using Regression and Multilevel/Hierarchical Models. New York, USA: Cambridge University Press, 2006

28. Ferrie JE, Kivimaki M, Head J, et al. A comparison of self-reported sickness absence with absences recorded in employers' registers: evidence from the Whitehall II study. Occup Environ Med 2005;62:74-9.

29. Statistical Yearbook of the Social Insurance Institution. Official Statistics of Finland. Helsinki, Finland: The Social Insurance Institution of Finland, 2005:170-1.

30. Heymans MW, de Vet HC, Bongers PM, et al. The effectiveness of high-intensity versus low-intensity back schools in an occupational setting: a pragmatic randomized controlled trial. Spine 2006;31:1075-82.

31. Linton SJ, Andersson T. Can chronic disability be prevented? A randomized trial of a cognitive-behavior intervention and two forms of information for patients with spinal pain. Spine (Phila Pa 1976) 2000;25:2825-31; discussion 2824

32. Glomsrod B, Lonn JH, Soukup MG, et al. "Active back school", prophylactic management for low back pain: three-year follow-up of a randomized, controlled trial. J Rehabil Med 2001;33:26-30.

33. Lonn JH, Glomsrod B, Soukup MG, et al. Active back school: prophylactic management for low back pain. A randomized, controlled, 1-year follow-up study. Spine (Phila Pa 1976) 1999;24:865-71.

34. Soukup MG, Glomsrod B, Lonn JH, et al. The effect of a Mensendieck exercise program as secondary prophylaxis for recurrent low back pain. A randomized, controlled trial with 12-month follow-up. Spine (Phila Pa 1976) 1999;24:1585-91; discussion 1592.

35. Von Korff M, Balderson BH, Saunders K, et al. A trial of an activating intervention for chronic back pain in primary care and physical therapy settings. Pain 2005:113:323-30.

36. Von Korff M, Moore JE, Lorig K, et al. A randomized trial of a lay person-led selfmanagement group intervention for back pain patients in primary care. Spine (Phila Pa 1976) 1998:23:2608-15.

37. Vahtera J, Korkeila J, Karlsson $\mathrm{H}$, et al. Sickness absence trends during and after long-term psychotherapy and antidepressant medication among depressive employees. Psychother Psychosom 2009:78:130-2.

38. Choi BK, Verbeek JH, Tam WW, et al. Exercises for prevention of recurrences of low-back pain. Cochrane Database Syst Rev 2010;(1):CD006555

39. Taimela S, Malmivaara A, Justen S, et al. The effectiveness of two occupational health intervention programmes in reducing sickness absence among employees at risk. Two randomised controlled trials. Occup Environ Med 2008;65:236-41.

40. Taimela S, Justen $\mathrm{S}$, Aronen $\mathrm{P}$, et al. An occupational health intervention programme for workers at high risk for sickness absence. Cost effectiveness analysis based on a randomised controlled trial. Occup Environ Med 2008;65:242-8.

41. Taimela S, Aronen P, Malmivaara A, et al. Effectiveness of a targeted occupational health intervention in workers with high risk of sickness absence: baseline characteristics and adherence as effect modifying factors in a randomized controlled trial. J Occup Rehabil 2010:20:14-20. 